$\star$ Rhizomes: Cultural Studies in Emerging Knowledge: Issue 34 (2018)

\title{
Graphic Science: Trinity and the Art of the Atomic Bomb
}

\author{
Pramod K. Nayar [1]
}

Abstract: This essay argues that Jonathan Fetter-Vorm's Trinity: A Graphic History of the First Atomic Bomb (2012) iconizes nuclear science in specifi ways. In the first section the essay examines modes of visuality that gives us a view of the scientist, the science and the contexts in which the two operate. The second section examines how the text unpacks a set of values, including those around politics, diplomacy and war, that determine and are determined by the science unleashed at Trinity. In the final section, the essay focuses on the political symbolism of the bomb.

Jonathan Fetter-Vorm's Trinity: A Graphic History of the First Atomic Bomb (2012) demonstrates an interesting use of the medium of the graphic nov to study the political, social and scientific history of the Manhattan Project and the first atomic bomb. Candida Rifkin argues in her reading of Trinity and accompanying graphic scientific biographies such as Jim Ottaviani et al's Fallout: J. Robert Oppenheimer, Leo Szilard and the Political Science the Atom Bomb (2001):

these works construct the figure of the scientist as a visual icon who is also a seeing subject. I propose that we consider scientific graphic biography as a specific genre that installs a biographical eye (as opposed to the auto/biographical I) to convey the complex relationship between empirical knowledge and affective experience that shapes lives caught between science and politics. (Rifkind 2)

Rifkind's focus is on the portrait of Oppenheimer, on his 'mythologization' (7). Oppenheimer was the icon of the atomic age and images of the scient as hero abounded, even during his 'dark years' at the hands of the US government. Instances of such iconization, writes David Hecht,

allowed people to see him as something other than just a scientist. Interestingly, such contextualization did not stem from an anti-science impulse-Oppenheimer remained very much a scientific icon. Perhaps paradoxically, however, his fans needed to sense a persona outside of science in order to admire him as a scientist. (945)

However, Trinity, I suggest, iconizes science as much as it iconizes the scientist, as the present essay seeks to demonstrate. By 'iconize' I mean lending a larger-than-life, quasi-mythic status meaning to the scientist and the science. I take iconization to include the semiotic arrangements of te: such as Trinityi, with Oppenheimer depicted as the gaunt, obsessive brooding, solitary 'hero', akin to the Romantic and/or Byronic, in many panels. But I also use iconize to signal the political understanding (by America, primarily) of the central role (to be) played by nuclear science itself in the remaking of the world order. The link between a 'pure' science project to the political symbolism of the A-bomb that Fetter-Vorm highlights, especial when depicting the American concerns around the Second World War and the putative effect of the bomb, and the subsequent Japanese surrender. are significant geopolitical events that invest the science of the A-bomb with enormous influence and value. It is, in other words, no longer a scientif laboratory fact but a geopolitical celebrity product and effect - and this new value-adding is the iconization in Trinity. This essay moves from FetterVorm's visual imaging of science that iconizes nuclear physics and technology, turns to the unpacking of values in the process of visual representati of science and concludes with a brief account of the political symbolism with which Fetter-Vorm ends his 'graphic history of the first atomic bomb.'

Before turning to the representation of science in the work, a few words regarding the genre of graphic scientific biography are in order. Candida Rif argues that Oppenheimer's representation in Trinity captures the essential 'unknowability' of the man, and therefore makes him the ideal subject for graphic biography (3). She also notes that Oppenheimer is drawn with the 'almost gaunt physical features that fit with inherited visual icons of scientific genius' (4). Contributing to the image of the isolated, hard-working genius is the separation of the personal from the professional, the priva from the public in Fetter-Vorm's representation. Fetter-Vorm embeds Oppenheimer within the intellectual history of the atom bomb. Throughout the text we are shown laboratories and classrooms where a large team of deeply involved - and bright - physicists, scientists, mathematicians discuss technicalities of building a bomb. We are given a history of nuclear physics - the Curies, Rutherford, Chadwick and others. He draws our attention ts the intellectual history within which the work of Oppenheimer may be situated and, except for occasional remarks about the exiled Jewish scientists he does not give us insights into the personal lives of the people involved in the making of the bomb. The text therefore approximates to the nineteenth-century model of scientific biography. Patricia Fara has argued that

Nineteenth-century scientific biographers separated intellectual histories from personal lives, and created heroic narratives to establish disciplinary forefathers ...[while] modern biographers and artists often seek to integrate the private and public, the emotional and rational facets of a subject (Fara 87).

However, Fetter-Vorm's although focus is clearly the bomb and the Manhattan Project. While a touch of the heroic is definitely an aspect of FetterVorm's depiction, the man is subsumed within the biography of the science project and the larger social, political and economic conditions in which the bomb was built, and of course, deployed. Understandably, since the focus of the work is the science of the bomb, the visual component of the narrative lays greater emphasis on this rather than on the individuals.

The 'Visuality of Scientificity' 
Adapting the work of Bruno Latour and others, Candida Rifkin argues that the harder the science the more it depends on and demands visual explanations (17). Images are the 'consensual visual representation of the thing believed to have taken place' (17). Oddly, however, this visual representation of the atomic bomb and the Manhattan Project, begins not with science but with the scientist, Oppenheimer, who, driving towards th test site (Trinity), enlightens his vehicle's driver on an ancient myth: of Prometheus. The image of the tower in which the atom bomb is placed is an image, one could say, of contemporary science. But this is preceded by the image of Zeus cursing Prometheus who, chained to the mountain, is having his liver eaten by a bird. The entire top half of this page (3) is taken up by the visual representation of the myth. Following this, we see Oppenheimer toss out the remnants of his cigarette and saying: 'he [Prometheus] gave humans knowledge for which we weren't ready' (3). In the la: panel on this page we see the tower that science built, and the text box that seems to label the tower states: 'another ancient secret was about to $b$ revealed' (3). Several things arrest us on this page's visual dynamics.

First, it clearly aligns Oppenheimer with the mythic Prometheus and anticipates via the myth, the punishment that awaits the unraveler of the (forbidden) knowledge of the atom bomb: ostracized, ridiculed and even rejected by the power (US government/Zeus) for his science, a science for which humanity is not, ostensibly, ready. The juxtaposition of myth and science on the same page therefore forces us into the proleptic, or oracular, reading of the science and the scientist: this is the fate that awaits him, Oppenheimer. Second, it enlists antiquity and mystery in describing the present-day science: the 'ancient secret' is at once fire and the atom bomb. Through this Fetter-Vorm mythologizes and romanticizes science itself: is a field of inquiry that unpacks ancient mysteries. It is not 'new' science, but a science that enables us today to finally reveal the world's oldest mechanisms of power and energy. Third, the two segments - the Prometheus myth and the atomic tower - are divided in terms of the page's layout the image of the vehicle in which Oppenheimer is travelling towards Trinity. The roof of the jeep appears to be either aflame or covered in cloud, roili down from the abode of the Gods. The Zeus location and that of Prometheus has clouds as their border, but this seems to grow tongues of flame th extend over Oppenheimer's vehicle. The image is striking because it offers us a mediating link between the ancient myth and contemporary science fire. Prometheus and Oppenheimer are both drawn on the same side of the page, in a nearly straight line, positioning Oppenheimer as a figurative descendant of Prometheus. Yet again this brings together myth and science: the mythic hero and the scientific hero are of the same lineage, and on the same side, for, as Spencer Clark has argued, the manner in which an author positions the actors vis-á-vis the historical events helps us, the readers, determine the constraints placed on an actor's agency (2013: 502-03). By locating Prometheus and then Oppenheimer at the centre of the image and its action, Fetter-Vorm clearly aligns the two under the category of historically heroic figures. One final point in this representation of mytr and science has to do with the flung-out cigarette. As the cigarette spins away into the clear white space of the New Mexican desert, we see the en is still aglow. I see this innocuous object as central to the page's rhetoric. Examining the role of objects in visual representations, Joanna Woodall (2012) has argued that even as the human protagonists, frame these objects, the objects frame the human interactions. The seemingly unimportant object in the frame, or even at the margins offers us a way of interpreting the scene unfolding (Woodall). If the tongues of flame on the roof of Oppenheimer's car serve as a mediating link, the cigarette with its glowing tip points to the human production and consumption of the fire/fiery obje Fire mediates the boundaries between humans and Gods, and now between (perhaps) life and death. Fire is what Prometheus secures; it is what Oppenheimer consumes in the form of the cigarette, and fire will be the possible outcome of the object in the tower, an object 'with the potential to burn as bright as a star.' The glowing cigarette tip enables us to see that at the centre of the ancient myth and modern science is a simple process: burning. The visuality of scientificity, then, is inaugurated not with the science qua science but with a linkage between an ancient myth and modern science, a linkage symbolized in the combustion process that is the cigarette: fire.

On the very next page, this visuality of scientificity gathers strength, and specificity. We are given a brief history of the discovery of radioactivity, through the representation of Marie and Pierre Curie working in 'Paris, France, 1898' (Fetter-Vorm 4). The scene is a laboratory - the first of the man' representations of laboratory space/life in Trinity - and the Curies are at a table carrying assorted bottles and devices, none of them distinguishable, being drawn as grey-black block objects. It is the Curies who set out to 'discover' the 'elements polonium and radium, which both emitted a mysterious energy.' Fetter-Vorm then draws the process of radioactive decay where U[ranium] becomes Th[orium], which becomes Ra[dium], which becomes $\mathrm{Po}[\mathrm{lonium}]$ which becomes $\mathrm{Pb}$ (plumbum, lead). These elements are only represented by their periodic table symbols, each written in thick lettering with shadows:

\section{$\mathrm{U}, \mathrm{Th}, \mathrm{Po}, \mathrm{Ra}, \mathrm{Pb}$}

We are told that 'radioactive decay ... is happening all around us in nature.' The visual representation of the breakdown of Uranium into its endelement, lead, is reduced to the letters of the alphabet and the periodic table. The representation of what science believes takes place in nature are 'theories' of how the process occurs in nature (Rifkind 19). This decay, summarized as a visual equation, is what the scientists would seek to first replicate, then harness, in controlled conditions: conditions that would produce the atom bomb.

This representation of radioactive decay, incidentally, is not given to us in a panel, as is the case with many of the technical-theoretical aspects of th science of the atom bomb, almost as though the scientific process and its representation cannot be confined to the panel. On the facing page for example, we are given, in sharp contrast to the lettered representation of radioactivity, the visual representation of the structure of the atom as discovered by Ernest Rutherford. The instantly recognizable planetary model of the atom depicts the nucleus with the electrons whizzing around it ir fixed pathways, and the textbox adjacent to this image tells us: 'but it was the astoundingly powerful forces circulating through this nucleus that captivated Rutherford's attention.' Again, as in the case of radioactivity, this visual imaging of the atom is unbounded. Together, placed on facing 
pages, the representation of radioactivity and the structure of the atom serve a key role in Fetter-Vorm's narrative: the energy of an atom and the atomic processes is literally and figuratively uncontainable. This interpretation of the image of the uncontainability and limitlessness of atomic energ'. as a potentially lethal force in Fetter-Vorm is invited by the stand-alone panel on page 5. Rutherford's face occupies the full panel with no vacant space (as opposed to the 'open plan' images of radioactivity and atomic structure). The textbox abutting into the Rutherford image says: 'to release those forces meant gaining access to a nearly limitless source of energy.' Rutherford has a speech bubble that says: 'some fool in a laboratory, if he finds the proper detonator, might just blow up the universe unawares' (Fetter-Vorm 5). Rutherford's words draw our attention away from the previous science drawing - of the process of radioactivity that 'is happening all around us in nature' - to the process that could be done in a laboratory. That if the previous image sought to inform us of a process that occurs in nature, Rutherford's quote directs us to the potentially dangerous harnessing, even if in the process of scientific inquiry, of these forces within a man-made, man-controlled environment: the laboratory.

The laboratory is a closed, even perhaps secret, space - secrecy, we know, was central to the Manhattan Project and to the transnational pursuit of nuclear energy itself - in which humans seek to unpack the processes of nature. Then, the laboratory is the space, as Svetlana Alpers (following the work of Peter Galison, but also Bruno Latour and Steve Woolgar on 'laboratory life') argues where 'the impact of the interference of the human observer in an account of natural phenomena' may be seen (Alpers 1998: 404). Rutherford is referring to the human observer, or catalyst, who, in the process of studying the phenomenon of atomic forces not in nature but in the laboratory, might 'just blow up the universe.' Taken together, the representation of the Curies' and Rutherford's laboratories, framed by and framing natural processes such as radioactive decay and atomic forces respectively, on the facing pages (4 and 5) constitute an interesting visual representation of the science of the atom bomb. Pages 8 and 9 have detailed visual images of the process of uranium fission. These are full-page images, essentially diagrammatic explanations of the process that is fission, except for five small panels. Within these panels, which serve as paratexts, or parergons to the fission process, Fetter-Vorm depicts: nuclear reactor chimneys, the radiation symbol, an x-rayed hand, a beaker with a liquid and a stirring rod. The juxtaposition gestures at the point Alpers makes: the natural decomposition or alteration of elements is engineered in laboratory/industrial conditions through human intervention. Science is 1 taking into humanized spaces of a process that occurs out in nature, perhaps at an entirely different level or order. Thus, the inset panels and laboratories are not just the parergon, the outwork, to science: they frame the science as an interpretation of a process even as the natural process instrumentalized within the laboratory. Later we are shown several sites of such an instrumentalization: the Universities of Chicago and California (Berkeley), Oak Ridge (Tennessee) and Hanford (Washington) where work on various aspects of the atom bomb are underway (20). There are other laboratory and industry images as well (36, 41-2, 46-7, 54-5, 57, and elsewhere). Similarly, there are many unbounded, non-panelled images of the fission reaction and other atomic processes $(44-5,48,52-3,58-9,70)$. Most of these pages depict humans on the margins and side-lines, mostly se into panels, of the chemical process which itself, as noted before, is not empanelled.

The representation of the atomic processes and the humans who observe, explicate and eventually control these processes exhibited in Fetter-Vorn visual rhetoric might be read in terms of what Peter Galison and Alexis Assmus have identified as the mimetic and the analytic experimentation mod (Galison and Assmus 1989). In the former the experiment seeks to reproduce conditions and processes from nature in the laboratory; in the latter th scientist seeks not to study the world reproduced but the real things that were made visible in the laboratory's conditions. I suggest that Fetter-Vorm visual rhetoric depicts the interplay between these two forms of experimentation. The numerous references to the state of the atom are made to the state as it occurs in nature, even as these atoms are relocated into laboratory chambers and test-tubes, indicating mimetic experimentation. Howev the laboratory and the scientist are not interested in the decay into half-life of the elements, since they wish to see now the effect of the implosion ot the atom: the energy released. This latter approximates to the analytic experimentation of Galison-Assmus because Oppenheimer and his cohort art not interested in the decay of the atom or its inherent instability which is its natural state. The laboratory process mimes the decay of the atom in the natural world, but is interested in the real elements - polonium, thorium, isotopes of uranium - and energy, produced in the laboratory's miming of tr process. The images and diagrams of the atomic processes - the science of the atom - framed by scientist-observers and laboratory settings - the science around the atom - oscillate between the mimetic and the analytic because they direct us simultaneously to a fact of natural decay, the artific of reproducing it in the laboratory, and the explication of the real constituents - atomic energy - of the process. It is because of this key visual narrative strategy of locating, framing and embedding the atomic process within the human, laboratory, institutional settings that we recognize the mimetic and analytic dimensions of the 'science of the atom.' Admittedly, Trinity focuses far more heavily on Oppenheimer the scientist, and far less attention is paid to the institutional structures and their politics that 'construct' the bomb. That is, Trinity remains very much a study of the man behil the bomb, although the last sections give us glimpses into the political frames within which the bomb was 'received', so to speak.

\section{Visual Analytics and Value}

When the bomb eventually explodes at the test site, the schematic diagrams and accompanying texts tell us what must have happened, offering us theory, or a way of seeing (theoria: to contemplate, view), the explosion's internal processes (Fetter-Vorm 70-1).

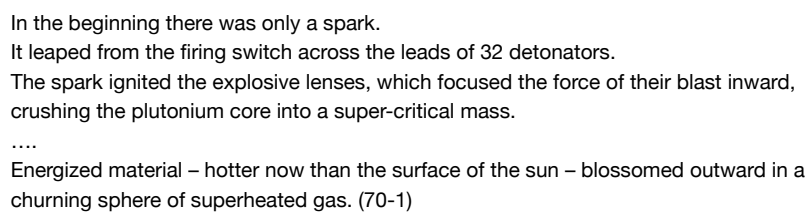

The images of these stages in the process show us the core of the atom splitting, the sparks flying and the core expanding. These spread across tw pages, but on the right of page 71 there is complete blackness. At the foot of the page is the test tower with a small glowing ball at the top, symbolizing the 'superheated gas' escaping. The four following pages are stunning in their images. $72-73$ is a set of black pages, with just the 
expanding fireball on top of the test tower placed at the bottom right of 73 . The text boxes located at the top left of 72 read: 'the rest of the world fe away into darkness...there was only the light' (72-3). On 74-75, similarly, is a set of black pages, and on 75 we have a massive white ball of fire. Pag 76 literally explodes. After the four black pages, 76 shocks us with a nearly-full page image of the mushroom cloud rising into the air. On the facing page numerous panels - the embedding and framing I spoke of in the preceding section - show witnesses shielding their eyes from the glare. The lowest panel shows Oppenheimer, also shielding his eyes, and the speech balloon carries his famous quote from the Gita: 'Now I become death, the destroyer of worlds' (77). On 78, we are shown in the top left corner, the scientists congratulating each other. The rest of the two pages, 78-79, is literally empty, except for a dark patch of ground with the 'twisted stumps of the steel tower.' The entire remaining area on the two pages is in blindil white. Two key text boxes state:

The Manhattan Project had transitioned over from the realm of science into that of politics, diplomacy, and war... the chain reaction had started. (79)

Fetter-Vorm forces something else about this test upon our attention with his representation of Oppenheimer and the images on the following pages His visual representation of the processes and product of the science takes us in an entirely different direction: of reevaluating the value of science. Catelijne Coopmans has argued that data possesses value, but visual imaging is a way of unlocking that value (2014: 38). I suggest that Fetter-Vorm unlocks not only the value of the science per se, depicts how the value of this science invites a larger consideration of non-scientific values and questions of the ethics of certain kinds of science and scientific pursuits.

Oppenheimer shades his eyes not to the blast at Trinity but to the future itself. We are told at the beginning of the narrative: 'what this bomb needed was a visionary' (21). Fetter-Vorm aligns this vision-ary behind the bomb, with the vision-ary who sees the future of mankind and the atomic age. Wr Oppenheimer recites the key phrase of having become death and the destroyer of worlds, as he shields his eyes to the blast, the representation - is no longer merely about the dazzling brightness of the scientific achievement, and the brilliance of the values that created the bomb or the military value of Oppenheimer's creation. Rather the image of the visionary Oppenheimer guarding his eyes proposes an entirely different value to the scienc destruction and death. This is the future Oppenheimer-the-visionary is reluctant to see with his eyes. This interpretation of Fetter-Vorm's visual representation of the moment of scientific and personal triumph is invited by the next image of the whitened space of the pages, with the twisted stumps of the test tower and the text box which imbricates science with politics.

Visual imaging then unlocks a wholly different set of values in Fetter-Vorm's text. Catelijne Coopmans terms such visual imaging 'artful revelation,' where visual analytics 'practitioners work to draw out those things that are properly contained within the data' (39). What Fetter-Vorm signals are the problematic values - politics, diplomacy, war - that encapsulate the non-scientific future of this science unleashed at Trinity, but are also brought ou into the open with that one explosion. In other words, with this set of disquieting images, Fetter-Vorm directs us to ponder over the other values of scientific knowledge, or the values locked into scientific knowledge that are appropriated by forces entirely unconnected to the science per se.

Fetter-Vorm will climax his visual analytics that unpack the different values of the bomb in his depiction of Hiroshima a few pages later. We are show the preparations on Enola Gay for the bomb and its launch (Fetter-Vorm 102-03). The actual drop occurs on the next page, with the top half of the page showing the events unfolding within the falling bomb: the fissile material thrust forward to strike the uranium in the nose of the bomb (nicknam Little Boy), which then catches fire and the chain reaction begins (58-9). Beneath this set of four images of the bomb racing towards Hiroshima is a whitened image of an exploding atom, with the city spread far below and to the right (104-05). Pages 106-7 map the destruction of the city, the burning winds, the 'churning heart of the explosion.' Pages 108-09 are devoted to 'Hiroshima [which] had become a desert,' with tendrils of smoke rising up into the sky. To the top left on 108 in a panel we are shown the mushroom cloud hanging over houses. Pages 122-123 are devoted to Nagasaki's destruction. The two pages are whitened, a boy lies dead next to his burnt bicycle, another crouches on the ground. The sky appears as series of fiery tongues reaching down towards the earth, and the only dark objects on these pages are the victims. Pages $124-25$ show the tongues fire as having reached the ground, and the boy on 123 is now standing. He is black/blackened and right in the midst of the fire waves. Pages $126-2 i$ the close-up, shows the boy, one arm charred, clothes hanging off him, caught in the fire wave. (The burning boy in Nagasaki of course reminds us । the burning girl in Vietnam, a few decades later in the cultural history of bombing.) Pages 128-29 show a river full of bodies, and its banks covered it bodies as well. We have been given the science of the second (Nagasaki) bomb, nicknamed Fat Man, earlier. It is a plutonium bomb, which used the 'finicky implosion method to start the nuclear chain reaction,' with a diagrammatic representation of the mechanics (115).

The 'artful revelation' that Coopmans speaks of is Fetter-Vorm's revelation of the costs of the bombs. In both these cases, it is possible to see how Fetter-Vorm moves beyond unpacking the science of the atom bomb to something more: the human and civilizational values destroyed with and by the bomb. When he unpacks the bomb's science, he does so by showing us the destruction wreaked by it. It is no longer the science in the graphic history of the bomb that is drawn for us.

\section{Political Symbolism and the Bomb}

Trinity concludes with an Afterword that takes us to present-day Northwest New Mexico, beyond Los Alamos. The ruins of the plant and testing site remain. Fetter-Vorm returns to the rhetoric he began with. He writes:

The rocks down there remain undisturbed, their secrets locked away.

But our senses fail us. If radiation were somehow visible ... we would see this power everywhere we looked. We would see it in the rocks, in our bones, in the air and the water. We would see that the secret of atomic power was stolen not from the gods, but simply from the earth. And we would remember that this atomic force is a force of nature.

As innocent as an earthquake. As oblivious as the sun.

It will outlast our dreams. (150-1) 
Here there are no images of the science of the bomb, only industrial ruins, abandoned buildings and empty landscapes. Cobwebs festoon the equipment.

Fetter-Vorm who began by citing myths around the capture of fire from the gods, before moving on to the secrets science unlocked, returns to the tı nature of the secrets revealed. The secrets are nature's secrets, he says, and depicts a landscape returning to and being reclaimed by nature in the form of overgrown equipment and animal life. The secrets are now back under the ground, even as the reclamation gestures at nature's way of buryi secrets: growing over human constructions.

There is one more aspect to the Afterword's visual rhetoric. Fetter-Vorm has already shown us the whiteness of the Trinity test site (78-9). Then he hi shown us the whiteness of landscapes of ruin - Nagasaki - after the bombs (122-6). He now rounds off the rhetoric of whiteness by depicting the post-test landscape of New Mexico in white as well. As political symbolism, Fetter-Vorm moves from the whiteness of science to the whiteness of destruction to the whiteness of buried secrets and dangerous legacies. The secrets, he says, lie under the ground in New Mexico, and inside nature itself. However, he also tells us that the stockpiling of nuclear weapons has averted the secrets of nature and transformed them into weapons-grad $\epsilon$ forces. The whiteness is an emptying of the power of science as Nature grows back over the test site. As a political symbol - white as the colour of peace is common knowledge - the whiteness of the Afterword is a potent reminder of the progression science has made from the first moments of testing to destruction and now wastelands.

Trinity, then, even as it focuses on the hero-scientist Oppenheimer, and the science of the atom bomb, does offer some insights into the politics of $\mathrm{t}$ bomb. For audiences unaware of anything beyond the explosions in Japan, Fetter-Vorm's work cautions us from seeing either science or the scienti as dissociated from the national and global geopolitics. This demotic account could go some way towards making the science a more 'amenable' discipline - there is the textbook explanation of nuclear reaction here! - even as it communicates the embedding of science in personal lives, institutional histories and national-global politics. Its visual rhetoric offers a critique of nuclearization even as it unpacks the science for us.

\section{Works Cited}

Fetter-Vorm, Jonathan. Trinity: A Graphic History of the First Atomic Bomb. New York: Hill and Wang, 2012.

Hecht, David K. 'The Atomic Hero: Robert Oppenheimer and the Making of Scientific Icons in the Early Cold War', Technology and Culture 49.4 (200 943-66.

Rifkind, Candida. 'The Seeing I of Scientific Graphic Biography', Biography 38.1 (2015): 1-22.

Fara, Patricia. 'Framing the Evidence: Scientific Biography and Portraiture', in Thomas Söderqvist (ed), The History and Poetics of Scientific Biograp Aldershot: Ashgate, 2007. 72-91.

Clark, J. Spencer. 'Encounters with Historical Agency: The Value of Nonfiction Graphic Novels in the Classroom', History Teacher 46.4 (2013): $489-5$ 502-03.

Woodall, Joanna. 'Laying the Table: The Procedures of Still Life', Art History 35.5 (2012): 976-1003.

Alpers, Svetlana. 'The Studio, the Laboratorv, and the Vexations of Art', in Caroline A. Jones and Peter Galison (eds) Picturing Science, Producing A London: Routledge, 1998. 401-417.

Galison, Peter and Alexi Assmus. 'Artificial Clouds, Real Particles', in David Gooding, Trevor Pinch, and Simon Schaffer (eds) The Uses of Experimer Cambridge: Cambridge University Press, 1989. 225-74.

\section{Notes}

1. An earlier, shorter version of this essay was presented as the keynote address 'The Medium of Destruction: Graphic Texts, Nuclear Science al the Making of the Atomic Bomb' at the international seminar, 'Words, Visuals and Beyond: Mediatization of Narrative Spaces', organized by tr Dept of English, Bharat Mata College, Kochi, Kerala, India, 22-23 Feb. 2018. I thank Dr Mini Abraham for persuading me to participate in the seminar.

\section{Cite this Essay}

https://doi.org/10.20415/rhiz/034.e08

RHIZOMES ISSN 1555-9998 $\star 230$ East Hall Bowling Green State University Bowling Green, $\mathrm{OH} 43403$

Editors: Ellen Berry and Carol Siegel. Reviews editor: Craig J. Saper. Technical editor: Helen J Burgess 